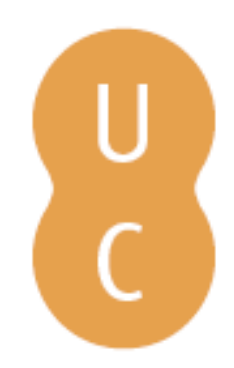

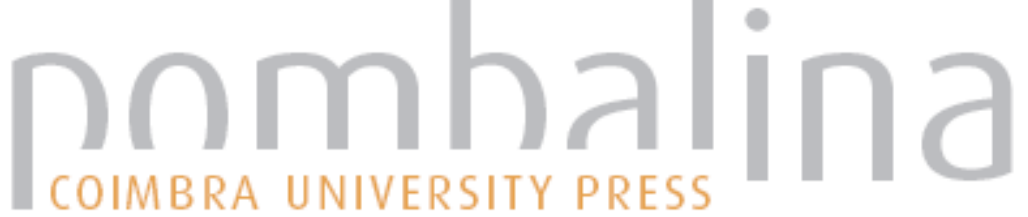

\section{Desastres naturais e gestão de risco no Brasil: características e contributos para o ordenamento territorial}
Autor(es): $\quad$ Pascoalino, Aline; Almeida, Lutiane Queiroz de
Publicado por: Imprensa da Universidade de Coimbra; RISCOS - Associação
URL persistente: Portuguesa de Riscos, Prevenção e Segurança
DOI:
URI:http://hdl.handle.net/10316.2/34933
DOI:http://dx.doi.org/10.14195/978-989-96253-3-4_133
Accessed : $\quad$ 26-Apr-2023 16:00:16

A navegação consulta e descarregamento dos títulos inseridos nas Bibliotecas Digitais UC Digitalis, UC Pombalina e UC Impactum, pressupõem a aceitação plena e sem reservas dos Termos e Condições de Uso destas Bibliotecas Digitais, disponíveis em https://digitalis.uc.pt/pt-pt/termos.

Conforme exposto nos referidos Termos e Condições de Uso, o descarregamento de títulos de acesso restrito requer uma licença válida de autorização devendo o utilizador aceder ao(s) documento(s) a partir de um endereço de IP da instituição detentora da supramencionada licença.

Ao utilizador é apenas permitido o descarregamento para uso pessoal, pelo que o emprego do(s) título(s) descarregado(s) para outro fim, designadamente comercial, carece de autorização do respetivo autor ou editor da obra.

Na medida em que todas as obras da UC Digitalis se encontram protegidas pelo Código do Direito de Autor e Direitos Conexos e demais legislação aplicável, toda a cópia, parcial ou total, deste documento, nos casos em que é legalmente admitida, deverá conter ou fazer-se acompanhar por este aviso.

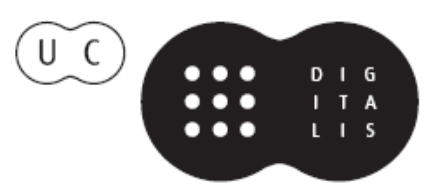



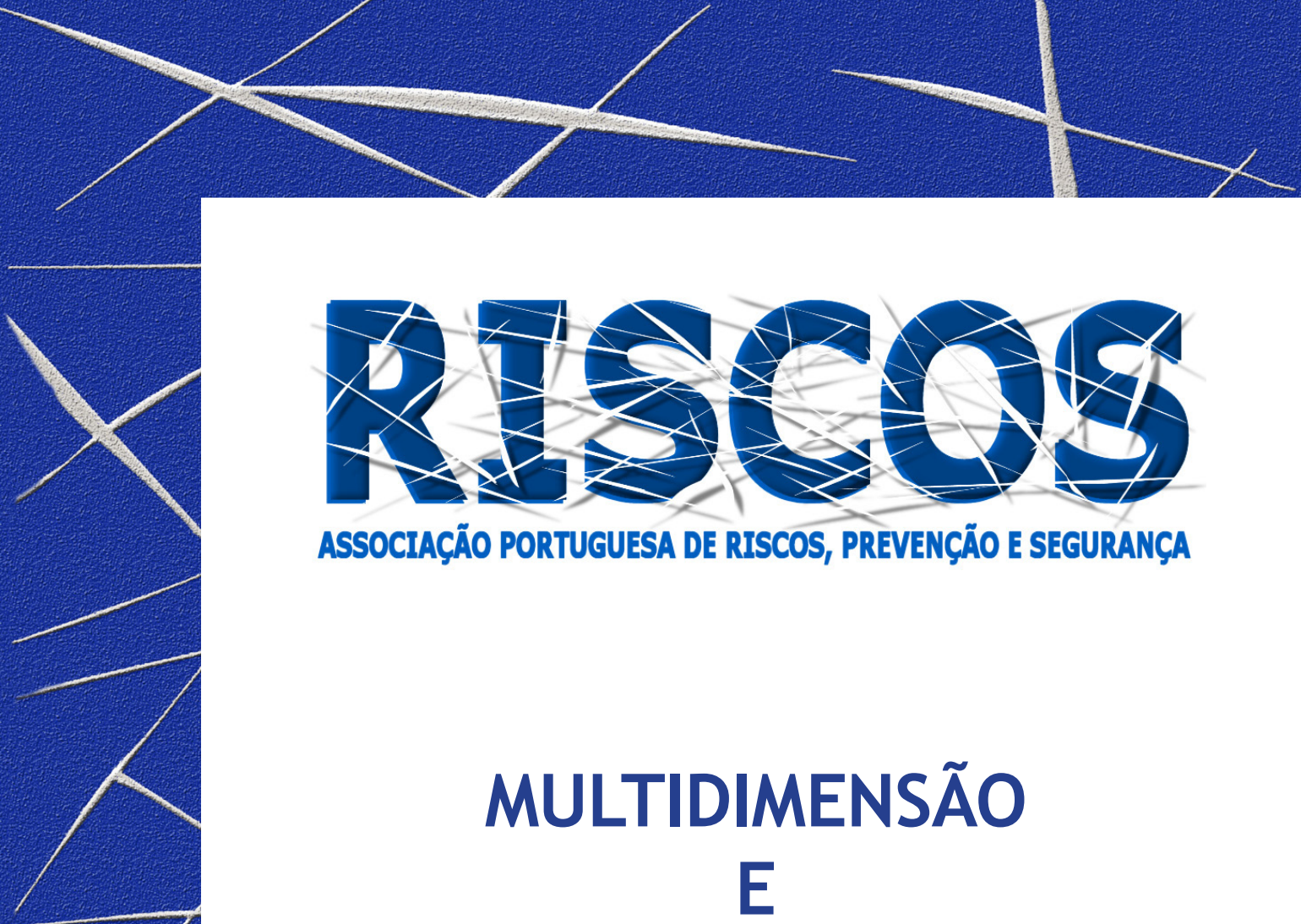

ASSOCIAÇÃO PORTUGUESA DE RISCOS, PREVENCCÃO E SEGURANÇA

MULTIDIMENSÃO

E
TERRITÓRIOS DE RISCO

III Congresso Internacional

I Simpósio Ibero-Americano

VIII Encontro Nacional de Riscos

Guimarães

2014 


\title{
DESASTRES NATURAIS E GESTÃO DE RISCO NO BRASIL: CARACTERÍSTICAS E CONTRIBUTOS PARA O ORDENAMENTO TERRITORIAL
}

\author{
Aline Pascoalino \\ Universidade Estadual Paulista - UNESP, Campus Rio Claro, Brasil \\ alinepascoalino@yahoo.com.br \\ Lutiane Queiroz de Almeida \\ Departamento de Geografia da Universidade Federal do Rio Grande do Norte - UFRN, Brasil \\ lutianealmeida@hotmail.com
}

\begin{abstract}
RESUMO
O estudo teve como objetivos verificar as características da gestão de risco e dos desastres naturais no território brasileiro, com ênfase nos de origem climática. Foram consideradas as bases de dados do EM-DAT e do Observatório Nacional do Clima e Saúde. No que tange à gestão de risco observou-se as propostas e ações destinadas à prevenção e recuperação perante desastres naturais. A sistematização dos dados permitiu verificar as diferenciações regionais na distribuição dos fenômenos desastrosos destacando-se a tipologia do desastre e suas consequências, áreas de maior prioridade para o direcionamento de investimentos públicos e a destinação orçamentária no processo de atuação do poder público pré e pós evento.

Palavras-chave: desastres, riscos climáticos, gestão ambiental, gestão da crise, mitigação.
\end{abstract}

\section{Introdução}

O mito de que no território brasileiro não ocorriam desastres naturais está sendo substituído nos últimos decênios pela preocupação de como gerir o território em situações pré e pós desastres. Esta postura segue devido a maior recorrência de eventos que resultam danos desastrosos à sociedade, o que revela a ineficiência dos processos gestores para antever situações potencialmente conflituosas. Neste início do século XXI os esforços têm convergido para o conhecimento da distribuição espacial dos desastres e seus respectivos danos, bem como para a sistematização de informações que possam ser utilizadas por pesquisadores e gestores, o que contribui à memória histórica dos eventos e à geração de uma cultura de risco, ainda inexistente no país.

No que tange à gestão de risco, um primeiro desafio constitui reconhecer as fragilidades existentes nos atuais 5.570 municípios, conforme as especificidades locais e regionais, para que possam ser criados bancos de dados que favoreçam todos os agentes envolvidos na prevenção dos riscos e na mitigação perante os desastres, além de dotar o território de infra estruturas de monitoramento em tempo hábil para se antecipar aos eventos, reduzindo impactos nas áreas de maior suscetibilidade. 0 que se observa no cenário brasileiro é a compreensão por diversas esferas da sociedade que é emergencial criar mecanismos gestores para que sejam implementadas medidas atreladas propriamente à gestão de risco e não dos desastres e da crise.

\section{Os desastres naturais no território brasileiro}

Registros fornecidos pelo EM-DAT (2014), referentes ao período de 1900-2014, revelam que eventos relacionados às inundações, aos movimentos de massa e às epidemias tiveram maior impacto em termos de danos humanos com maior fatalidade. As secas e as inundações, de grande notoriedade no território brasileiro, afetaram aproximadamente 68 milhões de pessoas nesse período (48 milhões pelas secas). No intervalo de 2000 a 2014 os desastres naturais de 
origem climática compreenderam 69 ocorrências, entre situações de inundações/enchentes (75\%), secas $(12 \%)$, tempestades $(9 \%)$ e temperaturas extremas $(4 \%)$. Dentre os desastres naturais de maior impacto destacam-se as inundações com movimentos de massa da Região Serrana do Rio de Janeiro (janeiro/2011), com o maior registro de mortes, aproximadamente 900 óbitos. Os desastres relacionados ao incremento hídrico tiveram maior fatalidade, mas as secas e estiagens produziram maior dano econômico. Eventos de inundações corresponderam a $74 \%$ da parcela afetada e as secas $24 \%$, em um total de 8.487 .635 pessoas afetadas.

Em se tratando da repercussão dos danos climáticos na dimensão regional do território brasileiro, de acordo com um levantamento histórico realizado pelo Centro Universitário de Estudos e Pesquisas sobre Desastres que culminou na sistematização do Atlas brasileiro de desastres naturais (CEPED/UFSC, 2012, p.91), verifica-se para o período de 1990-2010 aproximadamente 31.900 desastres no território nacional. O Nordeste, Sul e Sudeste do país apresentaram maiores taxas de ocorrência dos eventos, concentrando 94\%. No que concerne aos danos humanos, quase 103 milhões de pessoas foram afetadas em duas décadas, com maior taxa para a região Nordeste $(42 \%)$. A região Sul teve um terço das ocorrências $(34 \%)$, com taxa de população afetada pouco superior à metade da região Nordeste $(22 \%)$ e quase equivalente à da região Sudeste $(21 \%)$.

Com base nos dados extraídos do Observatório Nacional de Clima e Saúde (2014), para o intervalo 2000-2013, verificou-se que a maior parcela de afetados por desastres relacionados aos eventos climáticos ocorreu no incremento das precipitações com inundação (28.583.993 pessoas afetadas). Esse tipo de evento foi a principal causa de impacto no Centro-Oeste, Norte, Nordeste e Sudeste; enquanto na região Sul os desastres de causa eólica tiveram maior repercussão. Conforme a tipologia dos desastres, nas respectivas regiões, o Nordeste e Norte sofreram com intensa redução de chuvas, enquanto Sudeste e Sul também foram comprometidas por eventos de temperaturas extremas.

As regiões Nordeste e Sul apresentaram maiores taxas de afetados pela totalidade dos desastres (53\% e $26 \%$, respectivamente, com base em 62.755 .730 pessoas afetadas). A região Nordeste concentrou maior ocorrência de feridos e enfermos, enquanto o Sudeste concentrou os óbitos. Na apreciação por Unidade Federativa, Ceará, Santa Catarina, Bahia e Rio Grande do Sul foram os mais afetados. $O$ impacto na estrutura habitacional foi maior em Santa Catarina e Rio Grande do Sul (22\% e $12 \%$ de 2.187 .653 desalojados, respectivamente); e, Maranhão, Santa Catarina e Ceará (taxas entre 10\% e 12\% de 667.126 desabrigados). Os impactos à saúde foram mais significativos em Pernambuco, Rio de Janeiro, Santa Catarina e Amapá (entre 10\% e 18\% de 41.301 feridos); Ceará, Pará e Rio Grande do Norte (entre 11\% e 24\% de 241.652 enfermos) e Rio de Janeiro, Bahia e Santa Catarina (entre $10 \%$ e 33\% de 1.279 mortos).

\section{Características da gestão de risco no Brasil e contributos para o ordenamento territorial}

Os riscos climáticos resultam de processos naturais e das ações de uso e ocupação territorial, desse modo desconsiderar uma dessas dimensões pode gerar consequências conflituosas. 0 risco consiste na probabilidade de que algum evento aconteça; na concretização do evento, a magnitude de seu impacto pode adquirir característica de desastre, especialmente no espaço urbano que por ser heterogêneo, densamente habitado e irregularmente ocupado potencializa os efeitos danosos.

Conforme Almeida e Pascoalino (2012) o maior desafio para as instâncias governamentais é que seja invertida a lógica de investimentos públicos, enfatizando-se o trinômio: previsão, 
preparação e prevenção, o que significa análise de risco e popularização de uma cultura de risco e não uma cultura do desastre. A lógica prevalecente pode ser observada na destinação orçamentária para ações preventivas, emergenciais e de recuperação. Entre 2008 e 2011 apenas $35 \%$ do montante foi utilizado em prevenção e gestão de risco. A maior disparidade foi encontrada para o Estado de Santa Catarina, que em dezembro de 2008 teve 30\% de seus municípios atingidos por desastres nos anos seguintes só $1,3 \%$ do orçamento recebido foi destinado à prevenção.

Em 2012 o Governo Federal lançou o Plano Nacional de Gestão de Riscos e Resposta a Desastres Naturais (2012-2014). 0 plano propõe quatro vias de atuação: prevenção por meio da construção de obras estruturantes; mapeamento das áreas de risco; monitoramento e alerta promovendo a estruturação de uma rede nacional, e resposta a desastres por meio de medidas assistenciais e de reconstrução pós desastre (Brasil, 2014). Dentre 18,8 bilhões de reais a serem investidos, parcela de 15,6 bilhões de reais destinava-se às ações de prevenção.

Com base em informações obtidas junto ao Sistema Integrado de Administração Financeira do Governo Federal (SIAFI, 2014), verifica-se que as ações no ano de 2014 concentraram-se no auxílio emergencial financeiro e em ações da Defesa Civil, além de obras estruturantes (o que não deixa claro se preventivas ou remediadoras), com tímidos investimentos em mapeamento de áreas de risco e restabelecimento da normalidade em cenário de desastre. Tópicos como apoio a obras preventivas de desastres, mobilização e manutenção de grupo de apoio a desastres ou capacitação de agentes e comunidades em Defesa Civil seguiram sem nenhum tipo de investimento. Na distribuição orçamentária destinada à prevenção e recuperação de desastres fica claro que o montante investido no segundo caso é sempre superior ao primeiro.

Diante desse cenário sintetizam-se alguns delineamentos norteadores para reflexões sobre os desafios da gestão de riscos no território brasileiro, sinalizando para a carência de estruturas de governança voltadas para a informação e conhecimento do risco; o direcionamento eficiente de políticas públicas; a integração das dimensões escalares do espaço e das esferas do poder público; a prevenção e a resposta aos desastres e recuperação (Quadro I).

\section{Quadro I - Principais desafios a serem trabalhados pela gestão de risco no Brasil.}

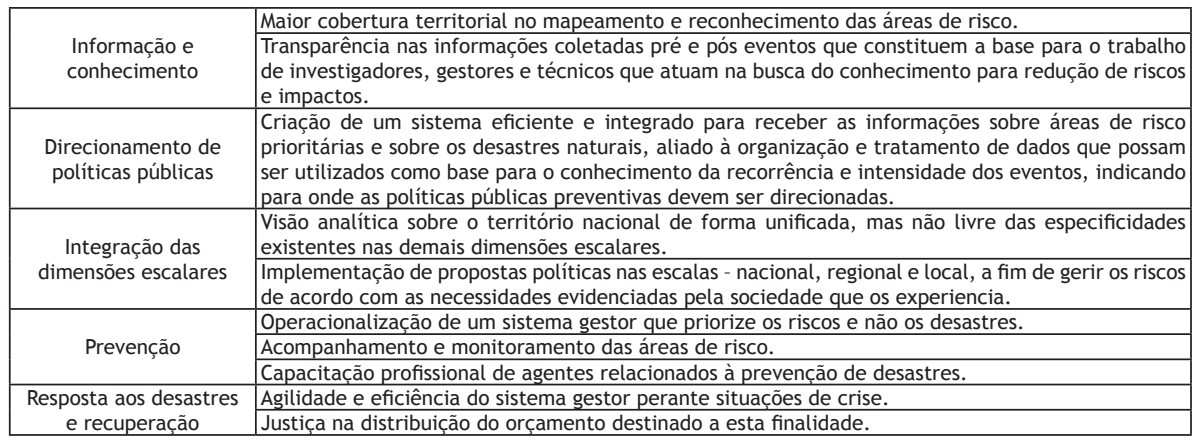

Org. Pascoalino e Almeida

A reprodução da postura vigente depara-se ainda com outros problemas que aliam o desconhecimento de áreas de maior risco à destinação final dos investimentos, demonstrando ineficiência na operacionalização da aplicação dos recursos, chocando a necessidade do recurso financeiro e o destino final do mesmo. Assim, enfrenta-se: ausência de conhecimento entre os 
municípios que necessitam de recursos e os que recebem os recursos; concentração de recursos em algumas Unidades Federativas e a carência em outras; ausência de critérios técnicos para distribuição dos recursos orçamentários; falta de integração entre órgãos governamentais, o que inviabiliza a circulação de informações; carência na dotação de infra estrutura territorial adequada pré desastre; ausência de transparência de informações; ausência da valorização de uma cultura do risco; entre outros fatores que inibem a gestão de risco propriamente dita, envolvendo previsão, preparação e prevenção.

\section{Conclusão}

Constata-se que em um primeiro momento segue o processo de reconhecimento das áreas de maior recorrência de desastres no país, constituindo as bases de dados existentes ferramentas que esclarecem quais eventos são mais frequentes e a diferenciação regional destes, bem como de seus impactos em termos das Unidades Federativas. Ao apreciar medidas direcionadas à prevenção e recuperação de desastres verifica-se um distanciamento entre as ações implementadas e as ações propostas, o que continua a reproduzir a persistência da gestão dos desastres em lugar da gestão de risco, com uma estrutura pautada em ações emergenciais e de recuperação pós desastre, tendo como resultante maiores danos para a sociedade e para as finanças públicas.

\section{Bibliografia}

Almeida, L. Q. de.; Pascoalino, A. (2012) - Riscos climáticos e a gestão do território no Brasil. In C. A. Silva, E. S. Fialho (Coords.), Concepções e ensaios da Climatologia Geográfica. (pp. 145-170). Dourados: UFGD Editora.

Brasil (2014) - Plano Nacional de gestão de riscos e resposta a desastres naturais 2012-2014. Ministério da Integração Nacional. Disponível em: http:/ /www.mi.gov.br [Acesso em 1 de setembro de 2014].

CEPED/UFSC (2012) - Atlas brasileiro de desastres naturais 1991 a 2010: volume Brasil. Centro Universitário de Estudos e Pesquisas sobre Desastres. Florianópolis: CEPED UFSC.

EM-DAT (2014) - The International Disaster Database. EM-DAT. Disponível em: http://www.emdat.be [Acesso em 1 de setembro de 2014].

Observatório Nacional de Clima e Saúde (2014) - Sistema de eventos extremos no Brasil. Observatório Nacional de Clima e Saúde. Disponível em: http://climasaude.icit.fiocruz.br [Acesso em 1 de setembro de 2014].

SIAFI (2014) - Execução orçamentária e financeira. Sistema de Administração Financeira do Governo Federal (SIAFI). Disponível em: http://www.tesouro.fazenda.gov.br/carrossel-siafi-03 [Acesso em 10 de setembro de 2014]. 